\title{
Abordagem do plágio nas três melhores universidades de cada um dos cinco continentes e do Brasil
}

MARCELO KROKOSCZ

Fundação Escola de Comércio Álvares Penteado

\section{INTRODUÇÃO}

Apresentar como próprio trabalho ou obra intelectual de outra pessoa configura plágio (Plágio, 2009). Manso (1987) demonstra que essa prática remonta à antiguidade romana e, notadamente, mantém-se com vitalidade até os dias atuais e de forma generalizada. Nos Estados Unidos, por exemplo, verifica-se ampla bibliografia e publicações sobre o assunto, sobretudo nos últimos sessenta anos (Hart; Friesner, 2004 apud McCord, 2008). Não obstante o comprometimento dos pesquisadores com o assunto, estudos indicam que $36 \%$ dos estudantes norte-americanos admitem fazer plágio (Plagiarism, 2009) e no Brasil 82,7\% dos professores alegam já se ter deparado com trabalhos acadêmicos que não foram feitos pelos alunos (Garcia, 2006).

No Brasil, a pesquisa acadêmica e o debate sobre o plágio ainda são incipientes, embora haja contribuições quanto ao assunto como: uma dissimulação dolosa na autoria de textos (Christofe, 1996); prática resultante de um desnorteamento ético (Vaz, 2006); hábito cristalizado de reprodução de textos e incapacidade de sumarização (Oliveira, 2007); motivo para o desenvolvimento de metodologias de detecção em cursos de educação a distância (Martins; Santana, 2003; Oliveira, M.; Oliveira, E., 2008); tema sobre o qual há pouco ou distorcido conhecimento (Barbastefano; Souza, 2007; Fachini; Domingues, 2008). 
Portanto, o plágio continua assunto relevante sobre o qual a reflexão em nosso país é exploratória. Além disso, concorda-se que se trata de uma problemática que tende a expandir-se, sobretudo em razão do advento da internet, pois a facilidade de acesso e manipulação da informação e a noção de que no campo virtual as regras e os princípios são diferentes, vêm intensificando a reprodução inescrupulosa das palavras e ideias de outros autores como se fossem próprias (Beasley, 2004 apud McCord, 2008; Vaz, 2006; Perissé, 2006).

Também cabe a observação de que o plágio está relacionado diretamente ao cotidiano acadêmico e, por caracterizar-se como prática desonesta, é incompatível com o escopo universitário de criação e desenvolvimento do conhecimento, constituindo-se demanda que requer imprescindível reflexão e posicionamento institucional. Para Christofe (1996, p. 34), o plágio é uma "prática danosa que deve ser vista com seriedade, não só no plano legal, mas principalmente nos meios intelectuais”. Essa noção é corroborada por estudos que demonstram a importância e necessidade da abordagem desse assunto no meio acadêmico, inclusive como conteúdo específico em disciplina relacionada à pesquisa (Barbastefano; Souza, 2007; Fachini; Domingues, 2008).

Considerando esses pressupostos, perguntou-se: como o plágio é abordado nas três melhores universidades de cada um dos cinco continentes e do Brasil, de acordo com as informações disponíveis em suas home page? A partir desse questionamento, os objetivos deste estudo foram: identificar e analisar as abordagens sobre o plágio adotadas nessas instituições; comparar as abordagens das melhores universidades mundiais com as abordagens das melhores universidades brasileiras; apresentar uma proposta de enfrentamento do plágio no Brasil.

Em relação aos objetivos propostos, esta pesquisa foi delineada como descritiva documental. De acordo com Marconi e Lakatos (2008), a técnica documental é utilizada para coleta de dados em fontes escritas, primárias e contemporâneas. A home page foi considerada uma fonte escrita primária por apresentar arquivos institucionais compilados pelas universidades e divulgados em meio eletrônico, em arquivo particular, mas de acesso público.

A amostra para este estudo resulta da seleção das três melhores universidades de cada um dos cinco continentes e do Brasil, de acordo com a segunda edição de 2009 do Webometrics Ranking of World Universities, elaborado pelo Cybermetrics Lab, um grupo de pesquisa espanhol do Conselho Superior de Pesquisas Científicas. O ranking é realizado com base no desempenho, visibilidade e impacto das universidades na internet, aferidos com base em indicadores como volume de documentos publicados, ligações externas, formatos de arquivos publicados e quantidade de citações a eles relacionados. Também são critérios de avaliação: comprometimento de professores e alunos; produção, resultado e aproveitamento de pesquisas; e o prestígio da instituição (Cybermetrics Lab, 2009). 
O universo de pesquisa corresponde a seis mil universidades, mas foram selecionadas para análise as três primeiras colocadas de cada continente e do Brasil. Portanto, a amostra selecionada é não probabilística intencional, pois o interesse nesta investigação é identificar a abordagem sobre o plágio em algumas universidades. Ainda que essa amostra não seja representativa do universo de pesquisa, é admitido que "tem sua validade dentro de um contexto específico" (Marconi; Lakatos, 2008, p. 38).

Para a identificação da abordagem que as universidades internacionais fazem em relação ao plágio, o procedimento escolhido foi o acesso à página principal (bome page) da instituição de ensino e a digitação do termo plagiarism no mecanismo de busca. Nas home page das universidades brasileiras, a busca foi realizada com a palavra plágio. Foram analisados os dados das duas primeiras páginas do resultado da busca. Os dados obtidos foram abordados qualitativamente, pois o delineamento desta pesquisa correspondeu a algumas das características apresentadas por Maxwell (1996) em relação a esse tipo de investigação, tais como enfoque específico, análise contextual e ênfase em palavras mais do que em números.

\section{REVISÃO DA LITERATURA}

Manso (1987) explica que o termo plagium remete ao segundo século antes de Cristo, época na qual uma lei romana (Lex Fabia de Plarigriis) utilizava esse termo para referir-se ao crime de furto (sequestro) de pessoas livres que eram feitas escravas para utilização pessoal ou comercial. $\mathrm{O}$ autor complementa, dizendo que, aparentemente, se deve ao poeta romano Marcus Valerius Marcialis (40 d.C.-104 d.C.) a associação do termo plagium "à apresentação de obra intelectual alheia como própria" (p. 10).

Historicamente associado à apropriação indevida de ideias alheias, no Brasil, na atualidade, o plágio é enquadrado juridicamente na lei n. 9.610/1998, que trata dos direitos autorais e considera contrafação a reprodução não autorizada de uma obra, "estando os infratores sujeitos às sanções civis e penais cabíveis" (Barbastefano; Souza, 2007, p. 4). Furtado (2002) considera que o plágio é previsto no Código Penal, no artigo 184, que trata dos Crimes Contra a Propriedade Intelectual e "traz o seguinte teor: Violar direito autoral: Pena - detenção, de 3 (três) meses a 1 (um) ano, ou multa”.

Embora seja prática antiga, enquadrada pelos códigos jurídicos, o plágio vem aumentando na atualidade. Pesquisar tornou-se muito fácil e instantâneo. Usando um computador e a internet como fonte de informação, é possível copiar e colar qualquer conhecimento com apenas alguns cliques. $\mathrm{O}$ crescimento da aprendizagem virtual (Educação a Distância) também tem sido observado como terreno propício para o aumento do plágio (McCord, 2008). 
Em geral, trabalhos acadêmicos plagiados sempre foram facilmente identificados por professores que conhecem o perfil dos seus alunos, o estilo de escrita deles e o nível de conhecimento que possuem. Contudo, Stanlick (2008) chama a atenção para o fato de que a prática de desonestidade na realização de trabalhos acadêmicos vem aprimorando-se. A autora defende a ideia de que é preciso desconfiar da capacidade intuitiva de detecção do plágio, ou simplesmente supor que uma rápida pesquisa em um buscador eletrônico já seja suficiente para identificá-lo e recomenda o uso de ferramentas eletrônicas de detecção do plágio.

Entretanto, cabe argumentar que é mais importante evitar o plágio do que reconhecê-lo e puni-lo, embora isso seja imprescindível para que a prática não se torne banal. Deve-se compreender o plágio de modo mais abrangente e não apenas de forma diagnóstica. É o que se infere de algumas fontes e estudos de referência da literatura.

Na busca por compreender a gênese do plágio, Schneider (1990) faz uma abordagem aprofundada do assunto, ponderando que "o plágio tem uma história. Mas essa história é complexa e contraditória: como tudo o que concerne à concepção, ela não tem mais desenlaces que começos” (p. 49).

Fazendo uma abordagem psicanalítica, o autor argumenta que a compreensão sobre a prática do plágio está relacionada mais com um problema de identidade de quem redige do que com a propriedade atribuída do texto copiado.

O plágio é uma doença, uma espécie de sonambulismo que não é nem o sono daqueles que não escrevem, nem a insônia do escritor. Involuntário, ele é uma alteração da memória, forte o bastante para reter a lembrança de uma leitura. Voluntário, ele assinala ainda uma doença, da moralidade, na melhor das hipóteses, da criatividade, na pior; em todo caso, um distúrbio da identidade. (Schneider, 1990, p. 156)

Indo além da conotação de chaga moral, Schneider (idem, p. 334) desenvolve uma reflexão em torno da ideia de intermitência do eu, discutindo a prática do plágio como um recurso utilizado por quem não tem nada a dizer, mas precisa autoafirmar-se por meio das ideias que expressa. Dessa necessidade decorre a "cleptomania intelectual" (idem, p. 387) do plagiário, "este alguém que não é ninguém” (idem, p. 479), que, diante do desejo inconfesso de ser alguém, se apropria e dissimula o que não tem, as palavras e ideias de outrem, pensando constituí-las numa nova pele, que, ainda que assim o seja, não passa de um "pensamento à flor da pele" (idem, p. 474), que longe está de assegurar a essência de um autor autêntico: aquele que tem estilo próprio porque encontrou "seu jeito de fundir ideias e palavras numa mesma matéria de pensamento" (idem, p. 433), o que é único e inimitável.

Outra maneira de entender a prática do plágio, ainda que mantenha o foco da discussão no sujeito (o plagiário), mais do que um problema de constituição de 
identidade, tem a ver com uma limitação ou incapacidade pessoal. Verifica-se, no estudo realizado por Oliveira (2007), a discussão sobre o plágio como resultado da dificuldade que o jovem universitário tem em produzir seu próprio texto. A autora afirma que a produção acadêmica desses estudantes seria apenas "preenchimentos" de modelos padronizados (Pécora, 2002), decorrentes de um desenvolvimento científico obtido na escola básica, deformado pelo hábito de se fazer transcrição literal (Salomon, 2001). Isso pode ser atribuído à preocupação cristalizada no campo educacional mais inclinada à verificação de aspectos relacionados à forma, como caligrafia, margens e adequação na apresentação, do que à originalidade do conteúdo redigido (Garcez, 1998).

Como alternativa para a superação dessa dificuldade, Oliveira (2007, p. 52) recomenda o uso da técnica de sumarização, "uma prática de compreensão de textos [...] que implica em selecionar [...] o que é relevante no/para o seu entendimento". Por meio dessa atividade, o redator identifica e extrai de um texto original as ideias essenciais e as reescreve em forma de síntese crítica, utilizando regras de apagamento e substituição.

Entretanto, Christofe (1996), ao discutir a possibilidade da existência de um texto em outro (intertextualidade), enfatiza que o plágio também se apresenta disfarçado de intertextualidade, a qual é desfigurada justamente pela intenção de que a fonte não seja recuperada, seja de forma explícita ou implícita. O que "se distingue da paráfrase, na medida em que não instaura o novo, repetindo apenas o já-dito" (p. 71).

A autora argumenta que, "no discurso científico, é preciso retomar a fala do outro e citar esse outro, para então propor uma reformulação e instaurar o novo. Caso contrário, o que se obtém é uma produção intelectual desestruturada e empobrecedora" (Christofe, 1996, p. 39).

Caracterizado dessa forma, além de atitude grave e desonesta do plagiário em silenciar e prejudicar o autor do texto original, conforme asseverado por Christofe (1996), pode-se supor que o plágio prejudica a credibilidade acadêmica e intelectual de quem o pratica, sobretudo quando realizado de forma deliberada e literal, compromete a reputação da instituição à qual está vinculado e não contribui em nada para o processo de produção e amor ao conhecimento.

Nesse sentido é que se faz muito oportuna a constatação do desenvolvimento de uma linha de reflexão sobre o assunto do ponto de vista da ética. Uma das argumentações verificadas alega que o problema do aumento da prática de plágio em trabalhos acadêmicos é uma "prática [que] denuncia um desnorteamento ético preexistente ao advento da internet” (Vaz, 2006, p. 160).

No campo virtual, diz o autor [Perissé, 2006], existe uma lei invisível, mas aceita por muitos, de que todos podem apropriar-se de tudo que está "acessável/ acessível" e que não há nada mais natural do que copiar o texto de um site sem 
citar a fonte. É comum também não considerar que a mesma obra copiada pode ter sido fruto de grande sacrifício de um autor honesto, mas também pode já ter sido "roubada" de outro. (idem, p. 171, grifos do autor)

Isso faz sentido considerando-se o referencial adotado por essa autora. Citando Quéau (2004) e Lévy (2000), entre outros, ela destaca que no espaço virtual os códigos de conduta não estão preestabelecidos e dependem do consenso da comunidade, constituindo-se grande desafio de adequação ética, ainda que requeiram os mesmos princípios fundamentais que orientam a vida humana no mundo real. Vaz (2006) arrola também a preocupação de outros autores, como, por exemplo, Rauch (2001), discutindo a necessidade de estabelecer-se uma nova ética que considere a especificidade das demandas e dos conflitos virtuais advindos do avanço tecnológico.

Essa linha de reflexão sobre o plágio (do ponto de vista da ética) parece ser a mais adotada por pesquisadores internacionais. McCord (2008, p. 42) defende que formas adequadas de enfrentamento do plágio têm a ver com o papel das próprias instituições de ensino e diz respeito à mudança da cultura institucional de "pegar trapaceiros" para a promoção da integridade acadêmica. O autor fundamenta-se em estudos que demonstram que políticas institucionais consistentes e apoiadas pelo corpo docente são mais eficazes se os próprios estudantes se percebem agindo de forma mais justa e sensata.

Um dos nomes mais recorrentes em publicações relacionadas a esse assunto é Donald McCabe, professor no curso de administração da Universidade de Rutgers. Por meio de uma de suas pesquisas sobre a ética acadêmica, cujo enfoque foi especificamente a comparação entre estudantes de escolas que utilizam e que não utilizam o que chamam de Códigos de Honra, foi verificado que a adoção de tais códigos pode ser uma iniciativa bem-sucedida:

Os alunos submetidos a um código foram menos propensos a trapacear, foram menos propensos a racionalizar ou justificar qualquer comportamento desonesto que tivessem admitido e eram mais propensos a falar sobre a importância da integridade e sobre como uma comunidade moral pode minimizar a desonestidade. Embora os alunos em ambos os tipos de escolas relatem que eles enganam e sentem muita pressão para enganar, estudantes que possuem códigos de honra aparentemente não sucumbem a estas pressões com a mesma facilidade que os estudantes que não têm um código. (McCabe; Trevino; Butterfield, 2001, p. 226-227, tradução nossa)

McCabe e Pavela (2005) argumentam ainda que os Códigos de Honra são formas eficazes encontradas por muitas universidades para reduzir práticas desonestas no ambiente acadêmico, sobretudo quando uma parte pequena dos estudantes é envolvida na sua elaboração e depois garantem a aceitação desses códigos por toda a comunidade educativa. 
Os autores enfatizam, por meio de dados de pesquisa, que nas instituições de ensino que adotam Códigos de Honra os níveis de desonestidade acadêmica são significativamente mais baixos e isso não se deve ao medo de ser punido, mas a uma "cultura que faz com que a maioria das formas de fraude grave seja socialmente inaceitável entre a maioria dos alunos" (McCabe; Pavela, 2005, tradução nossa).

A característica principal dos códigos de honra conforme a compreensão desses autores obedece a um padrão que eles chamam de "modificado", isto é, diferem dos códigos tradicionais por não se limitarem apenas a regras e sanções, mas por basearem-se no "significativo envolvimento dos alunos na promoção da integridade acadêmica e nas alegações de desonestidade acadêmica” (McCabe; Pavela, 2005, tradução nossa).

O sucesso de tais códigos depende, portanto, do envolvimento dos estudantes, os quais são caracterizados pelos autores como "Millennial generation", isto é, aquele grupo de pessoas que nasceram após 1982 (a chamada Geração Y). Os autores acreditam que esses alunos têm um grande potencial por serem "mais otimistas em relação ao futuro, mais empenhados com a comunidade, mais academicamente orientáveis, mais politicamente engajados e menos desmotivados" (McCabe; Pavela, 2005, tradução nossa). Resta, portanto, tirar proveito disto, requerendo a colaboração e investindo na liderança desses jovens. Se isso for obtido, enfatizam os autores, "inovações como códigos de honra tendem a prosperar" (McCabe; Pavela, 2005, tradução nossa).

Ademais, observando atentamente o modo por meio do qual as instituições de ensino internacionais enfrentam o plágio acadêmico, nota-se que a abordagem é abrangente, sendo a adoção do uso de códigos apenas uma das ações de uma política institucional voltada para a integridade acadêmica entre alunos, professores, orientadores, gestores etc.

Como exemplo, temos a implantação de Centros de Integridade Acadêmica, que visam ao desenvolvimento e cultivo da ética no meio acadêmico, proposta, esta, do Rutland Institute for Ethics da Universidade de Clemson, que mantém uma home page com informações e subsídios para as instituições interessadas em desenvolver tais centros. Dezenas de instituições de ensino ao redor do mundo são membros dessa iniciativa, dentre elas algumas que aparecem no topo dos rankings acadêmicos globais, como é o caso da Universidade de Harvard e do Instituto de Tecnologia da Califórnia (Clemson University, 2010).

Esse tipo de iniciativa tem o status de uma política institucional de enfrentamento do plágio que envolve diversos aspectos relacionados ao plágio e à integridade acadêmica, adotando ações diversificadas que envolvem realização de treinamentos, programas de conscientização, uso de tecnologias para deteç̧ão de plágio e a prescrição de punição aos alunos que violam as políticas institucionais (Hughes; McCabe, 2006 apud McCord, 2008, p. 42). 
Nesse caso, o plágio não é entendido como um problema isolado do aluno, mas como uma realidade que diz respeito à instituição em sua totalidade e requer propostas de enfrentamento que tenham essa característica de globalidade, ou seja, que envolvam os alunos, professores, orientadores e gestores.

Essa perspectiva parece muito apropriada porque vai além da postura policialesca de controle, perseguição e penalização, passando à adoção de estratégias tipicamente educativas que compreendem a conscientização, orientação e formação de uma postura calcada em valores. O que, dito enfaticamente, tem muito mais a ver com o escopo da instituição educacional!

\section{RESULTADOS}

Com o intuito de responder à pergunta proposta por este estudo e alcançar os objetivos elencados, passa-se a apresentar os resultados obtidos no levantamento feito sobre a abordagem do plágio nas melhores universidades dos cinco continentes e do Brasil, a fim de identificar e analisar as abordagens sobre o plágio adotadas nessas instituições; comparar as abordagens das melhores universidades mundiais com as abordagens das melhores universidades brasileiras; e apresentar uma proposta de enfrentamento do plágio no Brasil.

Inicialmente, foram selecionadas as instituições de ensino que compõem a amostra deste estudo. Para isso, foi utilizado o Webometrics Ranking of World Universities (Cybermetrics Lab, 2009). O Quadro 1 apresenta as três melhores universidades de cada um dos cinco continentes e a correspondente classificação entre as seis mil listadas no ranking.

Quadro 1 - Ranking das três melhores universidades por continente e posição no mundo. $2^{\mathrm{a}}$ ed. (Julho).

\begin{tabular}{|c|c|c|c|c|c|c|c|}
\hline AMÉRICA & & UROPA & & ÁSIA & & CEANIA & ÁFRICA \\
\hline $\begin{array}{ll} & \text { Massachusetts } \\
1 & \text { Institute of } \\
\text { Technology }\end{array}$ & 22 & Cambridge & & Tokio & 77 & $\begin{array}{l}\text { Australian } \\
\text { Nacional } \\
\text { University }\end{array}$ & 405 Cape Town \\
\hline 2 Harvard & 42 & Oxford & 26 & $\begin{array}{l}\text { National } \\
\text { Taiwan } \\
\text { University }\end{array}$ & 109 & Queensland & 509 Pretoria \\
\hline 3 Stanford & 46 & $\begin{array}{l}\text { Swiss Federal } \\
\text { Institute of } \\
\text { Technology }\end{array}$ & 49 & Kyoto & 137 & Monashi & 555 Stellenbosch \\
\hline
\end{tabular}

Fonte: Cybermetrics Lab (2009).

As três melhores universidades brasileiras classificadas, de acordo com esse ranking em 2009, são: Universidade de São Paulo (USP) (38), Universidade de Campinas (UNICAMP) (115\%) e Universidade Federal de Santa Catarina (UFSC) (134\%).

A seguir, são apresentados os resultados encontrados em cada uma das instituições por continente e no Brasil. 


\section{O plágio nas melhores universidades do continente americano}

O Instituto de Tecnologia de Massachusetts (MIT) (2007a) tem uma página exclusivamente preparada sobre a integridade acadêmica, com variado material de esclarecimento para o aluno quanto ao trabalho universitário: hábitos de estudos, conceitos relacionados ao plágio, orientações quanto ao uso de fontes, exemplos de violações etc. É disponibilizada uma versão impressa do Manual de Integridade Acadêmica do MIT (Massachusetts Institute Of Technology, 2007b).

A introdução do manual diz que o fato de ser aluno do MIT se deve à "demonstração de habilidade intelectual" e ao "potencial de contribuição para o pensamento humano e conhecimento". A instituição declara que um dos seus objetivos é contribuir para que homens e mulheres sejam preparados para oferecer ao mundo eficazmente sua especialidade. Portanto, espera que o aluno estude com objetividade, integridade e que faça tudo de forma honesta.

A Universidade de Harvard possui um programa considerado "a mais antiga tradição" da universidade. O "Writing Program” desenvolve a habilidade de escrita acadêmica do aluno. Na página do programa, são disponibilizados manuais e regras de escrita acadêmica (Harvard College, 2009).

O manual do aluno da Faculdade de Artes e Ciências, no item que trata de Desonestidade Acadêmica, recomenda a prevenção do plágio com a indicação de consulta aos manuais do estudante do "Writing Program". O texto termina com uma clara advertência:

[...] estudantes que, por qualquer razão, submeterem qualquer trabalho que não seja próprio ou que não destaque claramente as fontes, serão submetidos a ações disciplinares, e ordinariamente será requerido ao aluno o abandono da Universidade. (Faculty Of Arts And Sciences, 2009, p. 71, tradução nossa)

O Gabinete de Assuntos Jurídicos da Universidade de Stanford disponibiliza uma página eletrônica definindo o plágio de acordo com o Código de Honra da universidade. Apresenta uma lista de fontes que tratam do assunto para o esclarecimento da comunidade acadêmica e também elenca uma série de exemplos de casos de plágio com a correspondente sanção que, em geral, corresponde a um trimestre de suspensão e quarenta horas de trabalhos comunitários.

\section{O plágio nas melhores universidades do continente europeu}

A Universidade de Cambridge tem uma página sobre "Boas práticas acadêmicas e plágio", na qual há orientações sobre adequação às convenções acadêmicas utilizadas na universidade visando à sensibilização sobre o assunto e como evitá-lo. O conteúdo disponibilizado é dividido e orientado aos alunos e aos educadores. Entre as orientações dadas aos alunos é esclarecido o que significa plágio, como a Universidade de Cambridge o constata e quais são os procedimentos disciplinares 
adotados para combatê-lo, o que pode envolver entrevista com os envolvidos, suspensão e expulsão (University of Cambridge, 2010).

Os alunos são orientados que plágio é cópia e pode acontecer por meio de reprodução de textos sem indicação da fonte de consulta, interpretação de texto sem citação (paráfrase), utilização de ideias de outros autores como se fossem próprias, copiar e colar textos da internet, submissão de trabalhos de outras pessoas como sendo próprios. Também é disponibilizada uma lista de links com exemplos e procedimentos de combate ao plágio, adotados por outras universidades na Inglaterra e nos Estados Unidos.

A Universidade de Oxford trata do plágio como um assunto relacionado à política educacional da universidade. Em página eletrônica específica, define e descreve o plágio como uma violação da integridade acadêmica e defende a honestidade como um princípio do trabalho intelectual. Elenca uma série de formas de plágio, como a simples reprodução textual até a compra de trabalhos de "agências profissionais”. A universidade também se posiciona diante dos casos de plágio não intencional, ou seja, quando o fato acontece por descuido metodológico na indicação da fonte. Esses casos também são penalizados, pois a instituição entende que é responsabilidade do aluno aprender como evitar o plágio, indicar claramente suas fontes e se adequar às normas de escrita acadêmica (University of Oxford, 2006).

$\mathrm{Na}$ página institucional sobre o plágio, a universidade disponibiliza uma "Declaração de autoria" que o estudante deve entregar assinada com o trabalho acadêmico. Recomenda ainda que tal declaração seja adaptada e usada pelos departamentos e professores.

No Instituto Federal de Tecnologia da Suíça, a busca do termo "plagiarism" na página da instituição traduzida para o inglês, levou ao documento "Plágio: informações prévias aos estudantes". Trata-se de um decreto da Reitoria, no qual são apresentados a definição do plágio, uma lista de situações caracterizadas como plágio, procedimentos e medidas disciplinares a serem tomadas, que podem chegar até à retirada do título que tenha sido obtido por meio desonesto. $\mathrm{O}$ documento observa que "boa conduta científica exige a citação apropriada quando se usa ideias e teorias de outras pessoas, mesmo que sejam interpretadas pelo redator do trabalho". Lembra aos estudantes que o plágio viola o Código Disciplinar do Instituto Federal de Tecnologia da Suiça e deve ser comunicado à Reitoria e aos responsáveis.

Uma versão do mesmo documento é direcionada aos professores, com o acréscimo de orientações sobre estratégias de reconhecimento e prevenção do plágio, e informa que os trabalhos recebidos eletronicamente podem ser submetidos pelos professores a um software para deteç̧ão de plágio.

Em ambos os documentos há um modelo de "Declaração em relação ao plágio ao apresentar um trabalho escrito". Por meio desse documento, o aluno/ professor responsável pela submissão de qualquer trabalho acadêmico afirma estar 
esclarecido sobre o plágio por meio de nota explicativa, e que a elaboração do artigo está de acordo com as "normas gerais de citação de fontes" (Swiss Federal Institute OfTechnology Zurich, 2008).

\section{O plágio nas melhores universidades do continente asiático}

$\mathrm{Na}$ Universidade de Tókio, o documento "In your words or others?" (University of Tokio, 2006), elaborado pelo Programa de Escrita Crítica do Departamento de Inglês do campus Komaba, fornece explicações sobre o plágio, orientações para o uso de fontes e formas de elaboração de citações e referências. O conteúdo é apresentado com vários exemplos, inclusive sobre o modo correto de se fazer acréscimos/supressões e como indicar o uso de textos traduzidos. O documento observa que

[...] na Universidade de Tókio, a Faculdade de Artes e Ciências tem política clara sobre o plágio. O manual do estudante ([...] p. 24 na versão impressa, p. 18 na versão online em PDF) diz o seguinte: [...] Em alguns cursos, a avaliação é baseada nos trabalhos apresentados pelos alunos. Salvo instruções do professor, cada aluno é responsável pela elaboração do seu trabalho. (University OfTokio, 2006, p. 6-7, tradução nossa)

$\mathrm{Na}$ sequência desse texto, é observado que, no caso de trabalhos sem a identificação clara das fontes, todos os créditos obtidos no semestre serão anulados e o aluno não poderá realizar outros exames. Outros alunos envolvidos serão penalizados da mesma forma.

Em outro resultado da busca, encontra-se uma nota sobre plágio no programa de uma disciplina orientando que se trata de prática inaceitável (tolerância zero) e implica reprovação automática. A nota apresenta algumas características do plágio e recomenda que os estudantes vejam outras informações em links relacionados ao assunto, por exemplo, na Universidade de Indiana (EUA).

$\mathrm{Na}$ Universidade Nacional de Taiwan, a busca realizada na home page institucional traduzida para o inglês apresentou, entre os primeiros resultados obtidos, livros relacionados ao plágio recentemente adquiridos pela biblioteca da universidade. Contudo, o resultado mais importante foi a identificação de dois artigos relacionados ao plágio nas Diretrizes para o Exame de Obtenção dos Títulos de Mestre e Doutor (National Taiwan University, 2004, tradução nossa):

Artigo 6 - III - [...] Se houver plágio ou fraude na tese ou dissertação constatada por algum integrante da banca examinadora, o estudante perde o exame.

Artigo 10 - Se, após a atribuição do título, a universidade descobrir plágio ou fraude na dissertação ou tese do aluno, [...] o aluno deverá devolver o certificado de graduação e abandonar a universidade. 
Também foram identificadas observações sobre o plágio em documentos de disciplinas. No cabeçalho das orientações para a realização de um trabalho para o Departamento de Engenharia Elétrica, por exemplo, é destacado que plágio é um "comportamento não civilizado e que deve ser evitado a todo custo". O documento adverte aos alunos que os trabalhos entregues serão submetidos à detecção de plágio e os envolvidos terão a nota reduzida (National Taiwan University, 2010).

Em um programa de curso de composição de textos, o plágio aparece como conteúdo a ser estudado nos dois anos do curso. São estudados aspectos como: o que é, por que deve ser evitado e como evitá-lo (National Taiwan University, 2009).

Continua como conteúdo no segundo ano, destacado como assunto a ser enfatizado, sobretudo pela necessidade de ser evitado.

A busca realizada na Universidade de Kyoto obteve resultados praticamente nulos. O termo "plagiarism" aparece relacionado a textos acadêmicos, mas não é abordado institucionalmente. Há uma pequena menção ao assunto como um dos itens (accidental plagiarism) no programa da disciplina de Escrita Profissional (Kyoto University, 2009).

\section{O plágio nas melhores universidades do continente da Oceania}

A Universidade Nacional Australiana mantém uma página institucional na internet intitulada "Honestidade Acadêmica e Plágio". Os tópicos disponibilizados definem o que é honestidade acadêmica e plágio, apresentam a política e os procedimentos institucionais relacionados ao assunto, elencam dez dicas para evitar o plágio, orientam sobre o que os estudantes devem saber e costumam perguntar e também traçam algumas estratégias e soluções para o corpo acadêmico.

Para ampliar o esclarecimento e a conscientização da comunidade acadêmica, são indicados links para universidades de outras partes do mundo que também se preocupam com o mesmo assunto.

O Código de Práticas para Integridade Acadêmica dos Estudantes apresenta as expectativas da universidade em relação à integridade acadêmica dos alunos, esclarecendo que, em relação ao plágio, "cada aluno é responsável por garantir que está plenamente informado sobre os métodos apropriados de indicação das fontes nos trabalhos apresentados" (The Australian National University, 2009, tradução nossa).

Na página mencionada, que trata sobre honestidade acadêmica e plágio, entre as dicas para os estudantes evitarem plágio, é recomendado que conheçam o código institucional, observando que alegar desconhecimento não é desculpa para envolvimento em práticas desonestas. Observa que o manual do aluno também fala sobre plágio e honestidade acadêmica e que se ainda houver dúvidas, o estudante deve buscar orientação com professores, orientadores ou na repartição institucional responsável pela honestidade acadêmica. 
A última dica da universidade, tratada como a mais importante de todas, é direcionada à subjetividade do estudante, lembrando que o plágio compromete a reputação pessoal do aluno, que deve ser resguardada.

A home page da Universidade de Queensland possui uma página que trata da integridade acadêmica e plágio, considerando-os parte das informações essenciais aos estudantes, instrumento para incentivar a ética estudantil e informar a comunidade acadêmica sobre as normas institucionais.

O texto define e caracteriza o plágio, dividindo-o em duas categorias: intencional e não intencional. No caso de ocorrer sem a intenção do redator, por exemplo, em virtude do equívoco no uso de indicação da fonte, é observado que o responsável perderá pontos na avaliação e deverá corrigir os erros. Plágio intencional é tratado de acordo com as normas disciplinares da universidade, previstas no Estatuto n. 4, que trata da conduta estudantil (University Of Queensland, 2008).

A universidade incentiva o estudante a ler as políticas institucionais sobre honestidade acadêmica e plágio, disponíveis no manual da universidade, onde são apresentados de forma clara e compreensiva os princípios relacionados à prevenção do plágio. No manual, a universidade esclarece aos alunos que adota um software de detecção de plágio e recomenda que os estudantes utilizem essa ferramenta para melhorarem a qualidade dos trabalhos acadêmicos e evitarem o plágio.

A biblioteca da universidade contribui com a reflexão, apresentando uma página exclusiva sobre o assunto, intitulada "Plágio: evitando, cessando e detectando". Um material completo sobre o assunto é fornecido ao aluno, como orientações para uso de fontes (citações e referências) e dezenas de links relacionados ao assunto abordado por outras universidades ao redor do mundo.

A política institucional da Universidade de Monash considera o plágio "uma forma de obter vantagem acadêmica imerecida". A definição e orientações para se evitar o plágio são apresentadas em página exclusiva da home page institucional, como item complementar do conteúdo que trata das regras gerais de escrita. A instituição observa aos alunos que a entrega de trabalhos acadêmicos plagiados deverá ser explicada e os responsáveis podem ser penalizados com nota zero. Trabalhos com plágio deliberado são avaliados de acordo com o estatuto disciplinar da universidade (Monash University, 2009).

\section{O plágio nas melhores universidades do continente africano}

$\mathrm{Na}$ Universidade de Cape Town, os estudantes podem acessar na home page institucional o documento "Evitando plágio: um guia para estudantes", no qual o assunto é definido e são apresentadas as regras e políticas institucionais relacionadas. Em nota, o guia observa que as orientações e formas de se fazerem referências são disponibilizadas pelos professores, biblioteca e centro de escrita. 
A universidade recomenda que "todos os graduandos preencham uma declaração todas as vezes que submeterem um trabalho escrito para avaliação”. O texto da declaração é o seguinte:

1. Eu sei que o plágio é errado. Plágio é a utilização de outro trabalho como se fosse próprio.

2. Eu usei a normatização para elaboração de citações e referências. Cada texto interpretado e cópia literal neste ensaio / relatório / projeto / __ extraído do (s) trabalho (s) de outras pessoas foi atribuído por meio de citação e referências. 3. Este ensaio / relatório / projeto / é o meu próprio trabalho. 4. Eu não permito e não permitirei a ninguém copiar o meu trabalho com a intenção de passá-lo como seu próprio trabalho. 5. Eu reconheço que copiar um ensaio ou trabalho ou parte dele de qualquer outra pessoa é errado e declaro que este é o meu próprio trabalho. (University Of Cape Town, 2005, p. 2, tradução nossa)

O documento observa que o aluno deverá usar essa declaração na entrega de todos os trabalhos acadêmicos, em qualquer curso. Mesmo que o professor não solicite a declaração, é incumbência do aluno entregá-la junto com o trabalho após conversar com o professor. $\mathrm{O}$ corpo docente é orientado a não corrigir trabalhos acadêmicos que não tenham a declaração assinada.

Além disso, o aluno é orientado sobre as normatizações adotadas pela universidade e recomenda-se que o aluno procure a assistência da Biblioteca, do Centro de Escrita e do Centro de Informação e Alfabetização, bem como solicite aos professores indicações de home page que abordem o assunto.

Alunos que cometem plágio recebem nota zero no trabalho e poderão ser reprovados no curso; os coordenadores devem ser informados para encaminharem possíveis ações disciplinares de acordo com as normas institucionais. Casos de plágio significativo podem resultar até na expulsão do aluno. $\mathrm{O}$ texto termina explicando que o envolvimento com plágio pode chegar a ter consequências extra-acadêmicas: "Se você está se preparando para uma profissão, deve saber que uma condenação por fraude em trabalho acadêmico pode impedi-lo de licenciamento profissional, temporária ou permanentemente" (University Of Cape Town, 2005, p. 2, tradução nossa).

A Universidade de Pretória apresenta em sua home page um Documento de Política para o Plágio que "serve como informação sobre o que constitui o plágio, considerado uma grave ofensa, e quais as possíveis consequências para o estudante culpado" (University Of Pretoria, 2009, grifo do autor, tradução nossa).

O documento citado caracteriza os tipos de plágio e faz um destaque especial para o caso de paráfrase (citação indireta) sem indicação de fontes, observando que 
isso em algumas culturas é considerado normal, contudo enfatiza que de acordo com as normas internacionais isso não é aceitável e é criminalmente condenável.

Em relação às sanções, o documento observa que, na primeira transgressão, o problema pode ser resolvido entre o professor e o estudante, resultando na redução da nota de avaliação do trabalho e informação à coordenação. No caso de recorrência à infração, o estudante é encaminhado à sindicância disciplinar, podendo ser suspenso das atividades acadêmicas da universidade, e, nos casos mais graves, das atividades em todas as universidades sul-africanas. Na página também são dadas algumas instruções sobre a elaboração de citações e referências e, no final do texto, há um link para que sejam solicitadas outras informações sobre plágio.

Na busca realizada com o termo "plagiarism" na Universidade de Stellenbosch, não foi encontrada uma página específica sobre o assunto e também não foi identificado se a universidade tem política institucional definida sobre plágio. Os resultados da busca aparecem relacionados a um workshop realizado em 2008, no qual o plágio era um dos assuntos abordados e a outro, ocorrido em maio de 2009, no qual foi apresentado o uso de uma ferramenta eletrônica de deteç̧ão do plágio.

\section{O plágio nas melhores universidades brasileiras}

A Universidade de São Paulo não apresenta conteúdo institucional relacionado ao plágio. Uma página do Instituto de Física apresenta uma reflexão, a partir da constatação de plágio em trabalhos entregues por alunos, cuja finalidade é informar aos discentes que a reprodução de documentos sem a devida indicação de autoria e identificação da fonte consultada consiste em comportamento reprovável em qualquer ambiente, real ou virtual (Haar; Rezend; Guimarães, 2005).

Em um link do Instituto de Matemática e Estatística, o plágio é tratado como "inadmissível”, recomenda-se "a reprovação do aluno na disciplina" cursada e que a ocorrência seja reportada à Comissão de Graduação para outros encaminhamentos (Universidade de São Paulo, 2009a).

Outros resultados da busca referem-se aos casos de professores denunciados por plágio nos últimos anos. Também aparece um artigo científico sobre plágio, hospedado na página da Faculdade de Economia e Administração, resultado de pesquisa realizada por acadêmicos de outra instituição de ensino superior (Universidade de São Paulo, 2009b).

$\mathrm{Na}$ Universidade Estadual de Campinas não foi encontrada nenhuma abordagem oficial da instituição sobre o plágio na busca eletrônica, mas foi possível identificar a menção ao assunto em um programa de disciplina (Universidade Estadual de Campinas, 2005).

Em geral, a busca sobre o assunto na home page institucional resultou em uma série de links para listas de discussões particulares sobre plágio. Em relação 
à universidade, os conteúdos mais relevantes referem-se a trabalhos acadêmicos que foram desenvolvidos sobre o assunto, notadamente a tese de Christofe (1996), citada neste estudo.

Entre os resultados da busca realizada na home page da Universidade Federal de Santa Catarina, foram encontrados links para documentos de professores com orientações sobre a importância de se evitar o plágio em trabalho acadêmico (Bornia, 2009), menção em programa de disciplina (Universidade Federal de Santa Catarina, 2006) e artigos acadêmicos sobre o assunto.

Também foi encontrado um documento com orientações sobre o plágio, contudo, infelizmente, nesse mesmo documento foi constatada a reprodução literal de trechos inteiros sem citação e referência de outro texto, o que caracteriza plágio direto (cópia literal).

Embora não se faça aqui a demonstração documental do fato verificado, a alusão a ele corrobora o que parece evidente: a forma como o plágio acadêmico vem sendo enfrentado pelas instituições de ensino no Brasil pode ser considerado, da melhor forma, muito incipiente e, da pior forma, chega a ser constrangedor.

\section{Sistematização dos dados coletados}

Considerando-se as ponderações encontradas na literatura que foi revisada, bem como a identificação das abordagens adotadas pelas universidades em relação ao plágio, propõe-se o agrupamento das informações obtidas nas seguintes categorias:

Medidas institucionais: 1. Hotsite institucional com conteúdo exclusivo sobre plágio; 2. Política Institucional sobre o plágio; 3. Disponibilização de guias, manuais e/ou documentos oficiais sobre o assunto; 4. Comissão de Integridade Acadêmica, Comitê Disciplinar, Sindicância etc.

Medidas preventivas: 1. Orientação: Ações de esclarecimentos da comunidade educativa (Definição e/ou caracterização do plágio; documentos de professores, conferências, workshops, formulários de declaração da idoneidade do trabalho, indicação de links para aprofundamento sobre o assunto; etc.); 2. Capacitação: Ações de instrumentalização, tais como cursos, atividades, exercícios, abordagem disciplinar, elaboração de manuais de escrita acadêmica, tópico de disciplina ou orientações para a elaboração de trabalhos acadêmicos; 3. Formação: Apelo a princípios e valores, ações voltadas para a importância do compromisso e desenvolvimento de princípios éticos, como a preservação da reputação do aluno.

Medidas diagnósticas: 1. Disponibilização e/ou utilização de softwares de deteç̧ão do plágio.

Medidas corretivas: 1. Descrição do plágio nos códices institucionais (Código de Honra; Código de Ética etc.); 2. Penalização (advertência, suspensão, expulsão etc.).

Organizadas essas informações em um quadro sinótico, temos a representação de todas as medidas encontradas nas home page das melhores universidades nos cinco continentes e no Brasil, conforme a seguinte distribuição: 
Quadro 2 - A Australian National University, Queenland e Monash adotam medidas diagnósticas de plágio

\begin{tabular}{|c|c|c|c|c|c|c|c|c|c|c|c|c|}
\hline \multirow{2}{*}{ 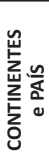 } & \multirow{2}{*}{ 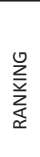 } & \multirow{2}{*}{$\begin{array}{l}\text { MEDIDAS } \\
\text { UNIVERSIDADES }\end{array}$} & \multicolumn{4}{|c|}{ MEDIDAS INSTITUCIONAIS } & \multicolumn{3}{|c|}{ MEDIDAS PREVENTIVAS } & \multirow{2}{*}{$\begin{array}{c}\text { MEDIDAS } \\
\text { DIAGNÓSTICAS } \\
1 \\
1\end{array}$} & \multicolumn{2}{|c|}{$\begin{array}{c}\text { MEDIDAS } \\
\text { CORRETIVAS } \\
\end{array}$} \\
\hline & & & 1 & 2 & 3 & 4 & 1 & 2 & 3 & & 1 & 2 \\
\hline \multirow{3}{*}{ 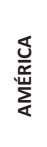 } & 1 & $\begin{array}{l}\text { Massachusetts } \\
\text { Inst. of Tech. }\end{array}$ & $\checkmark$ & $\checkmark$ & $\checkmark$ & $\checkmark$ & $\checkmark$ & $\checkmark$ & $\checkmark$ & & $\checkmark$ & $\checkmark$ \\
\hline & 2 & Harvard & $\checkmark$ & $\checkmark$ & $\checkmark$ & & $\checkmark$ & $\checkmark$ & & & $\checkmark$ & $\checkmark$ \\
\hline & 3 & Stanford & $\checkmark$ & $\checkmark$ & $\checkmark$ & $\checkmark$ & $\checkmark$ & $\checkmark$ & & $\checkmark$ & $\checkmark$ & $\checkmark$ \\
\hline \multirow{3}{*}{ 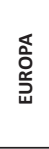 } & 22 & Cambridge & $\checkmark$ & $\checkmark$ & $\checkmark$ & $\checkmark$ & $\checkmark$ & $\checkmark$ & & $\checkmark$ & $\checkmark$ & $\checkmark$ \\
\hline & 42 & Oxford & & $\checkmark$ & $\checkmark$ & $\checkmark$ & $\checkmark$ & $\checkmark$ & & & $\checkmark$ & $\checkmark$ \\
\hline & 46 & $\begin{array}{l}\text { Swiss Fed. Inst. of } \\
\text { Technology }\end{array}$ & & $\checkmark$ & $\checkmark$ & $\checkmark$ & $\checkmark$ & & & $\checkmark$ & $\checkmark$ & $\checkmark$ \\
\hline \multirow{3}{*}{ 屁 } & 24 & Tokio & & $\checkmark$ & $\checkmark$ & & & $\checkmark$ & & $\checkmark$ & & $\checkmark$ \\
\hline & 26 & $\begin{array}{l}\text { National Taiwan } \\
\text { University }\end{array}$ & & & $\checkmark$ & & $\checkmark$ & $\checkmark$ & & $\checkmark$ & $\checkmark$ & $\checkmark$ \\
\hline & 49 & Kyoto & & & & & & $\checkmark$ & & & & \\
\hline \multirow{3}{*}{ 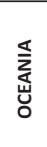 } & 77 & $\begin{array}{l}\text { Australian Nacional } \\
\text { University }\end{array}$ & $\checkmark$ & $\checkmark$ & $\checkmark$ & $\checkmark$ & $\checkmark$ & $\checkmark$ & $\checkmark$ & & $\checkmark$ & $\checkmark$ \\
\hline & 109 & Queensland & $\checkmark$ & $\checkmark$ & $\checkmark$ & $\checkmark$ & $\checkmark$ & $\checkmark$ & $\checkmark$ & & $\checkmark$ & $\checkmark$ \\
\hline & 137 & Monash & $\checkmark$ & $\checkmark$ & $\checkmark$ & & $\checkmark$ & $\checkmark$ & & & $\checkmark$ & $\checkmark$ \\
\hline \multirow{3}{*}{ 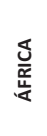 } & 405 & Cape Town & & $\checkmark$ & $\checkmark$ & & $\checkmark$ & $\checkmark$ & $\checkmark$ & & & $\checkmark$ \\
\hline & 509 & Pretoria & & $\checkmark$ & & $\checkmark$ & $\checkmark$ & & & & & $\checkmark$ \\
\hline & 555 & Stellenbosch & & & & & $\checkmark$ & & & & & \\
\hline \multirow{3}{*}{ 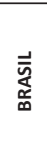 } & 38 & $\begin{array}{l}\text { Universidade de São } \\
\text { Paulo }\end{array}$ & & & & & $\checkmark$ & & & & $\checkmark$ & $\checkmark$ \\
\hline & 115 & $\begin{array}{l}\text { Universidade } \\
\text { Est. de Campinas }\end{array}$ & & & & & $\checkmark$ & & & & & \\
\hline & 134 & $\begin{array}{l}\text { Univ. Fed. de } \\
\text { Sta. Catarina }\end{array}$ & & & & & $\checkmark$ & $\checkmark$ & & & & \\
\hline
\end{tabular}

Fonte: Elaboração do autor.

Observando os resultados, é possível verificar que há semelhanças na abordagem feita em relação ao plágio pelas universidades dos continentes americano, europeu e australiano. As universidades da Oceania apresentam, nas suas respectivas home page, a abordagem mais completa de acordo com a sistematização elaborada neste estudo, desenvolvendo integralmente o conjunto de ações classificadas como medidas institucionais, preventivas, diagnósticas e corretivas.

De acordo com a análise dos dados, nota-se que a Australian Nacional University (Oceania) e a The University of Queensland (Oceania) são as únicas instituições de ensino que realizam todas as ações de enfrentamento do plágio classificadas neste estudo.

A abordagem das universidades dos continentes americano e europeu, excetuando-se o Massachussets Institute of Technology (América), diferem da Oceania pelo fato de não ter sido verificado em suas home page observações relacionadas diretamente à importância da preservação e desenvolvimento de valores pessoais e princípios éticos. 
Aliás, pode-se notar por meio do quadro sinótico, que esta é uma das ações menos abordadas em todas as universidades, o que denota um campo pouco explorado, embora a literatura indique a importância de investir no desenvolvimento ético como ação mais eficaz no combate ao plágio (McCabe; Pavela, 2005; Vaz, 2006; McCord, 2008).

Somente quatro das universidades estudadas fazem menção em suas home page à importância do comprometimento ético como recurso de controle, enfrentamento e superação do plágio: Massachussets Institute of Technology (América); Australian Nacional University (Oceania); The University of Queensland (Oceania) e University of Cape Town (África).

As ações das universidades dos continentes asiático e africano são parecidas e atendem parte das ações classificadas neste estudo. Nenhuma das melhores universidades desses continentes apresenta uma página oficial sobre o assunto, contudo nas buscas em suas home page são encontradas outras informações oficiais sobre o plágio, bem como um conjunto de ações com intuito preventivo.

A quantidade de ações de abordagem sobre o plágio encontrada nas home page das melhores universidades brasileiras é menor se comparada às melhores universidades dos cinco continentes. Não foram encontradas abordagens institucionais sobre o assunto por parte dessas universidades na busca realizada com o termo "plágio" em suas respectivas home page, aspecto que destoa das outras instituições pesquisadas neste estudo. Também não foi possível identificar por meio da busca medidas claras de tomada de decisão institucional das melhores universidades brasileiras, tais como regras, acompanhamento e penalização em relação à constatação de ocorrência de plágio em trabalhos acadêmicos, o que foi comumente encontrado nas home page das melhores universidades do mundo.

A ação mais comum nas abordagens de todas as universidades estudadas é a ação de orientação. A ação menos comum é a de natureza ética, caracterizada por apelo a princípios e valores. Essas ações foram classificadas neste estudo como preventivas.

Em geral, foi possível encontrar nas home page das universidades estudadas: documentos com esclarecimentos sobre o plágio (o que é e como ocorre); documentos de professores relacionados ao assunto; realização de conferências, workshops etc.; formulários de declaração da idoneidade do trabalho; indicação de links para aprofundamento sobre o assunto.

\section{DISCUSSÃO}

Considerando a fundamentação teórica e os dados obtidos neste estudo, a primeira constatação evidente é que o plágio é um problema crônico cujo enfrentamento não pode prescindir de uma abordagem que leve em consideração a complexidade na qual está inserido, o que diz respeito no mínimo a três sujeitos em especial: quem copia (o redator), quem é copiado (o autor) e quem é espectador (o leitor). 
O papel mais coadjuvante nessa cena é do autor, o responsável original do conteúdo, que muitas vezes sequer sabe que foi copiado. A atenção maior em relação à ocorrência do plágio tem a ver com quem protagoniza: o redator e o leitor.

Primeiramente, cabe um cuidado com o reducionismo penalizante sobre o redator, que pode ser considerado de uma forma simplista e estereotipada como um "ladrão de palavras". Entretanto, essa é uma maneira superficial de tratar o problema que, em geral, é bem mais complexo. A própria consideração de roubo é discutível em relação ao plágio. O jurista americano Richard Posner (2007) brilhantemente, argumenta que a definição de "roubo literário" é incompleta e imprecisa, pois considera um roubo o que é simplesmente uma cópia, além do que o autor original continua tendo suas ideias, "ainda tem seu livro, diferentemente de quando se rouba seu carro" (p. 11).

É preciso considerar na discussão sobre o plágio, quando abordado na perspectiva do redator (plagiário), o aspecto que diz respeito às limitações relativas à incapacidade de produção de ideias. Nesse caso, a simples imputação de responsabilidade e penalização ao redator é impingir exclusivamente ao indivíduo um ônus que também diz respeito a outras pessoas.

Considere-se aqui a responsabilidade da própria instituição de ensino (o leitor) em cumprir de forma eficaz seu papel educativo, seja instrumentalizando adequadamente e de forma eficiente a capacidade de escrita e também se servindo de todas as medidas disponíveis que contribuam para a originalidade do conhecimento produzido.

Destacamos aqui a importância do trabalho desenvolvido na disciplina de metodologia científica, presente em praticamente todos os cursos de nível superior. Pode-se contemplar a abordagem dessa temática como conteúdo do programa de ensino dessa disciplina, enfatizando-se a instrumentalização técnica dos estudantes na produção de textos, seja utilizando os recursos de elaboração textual, como é o caso do uso de paráfrases, bem como a correta indicação de autores (citações) e identificação dos documentos consultados (referências). Apesar do estudo feito por Fachini e Domingues (2008) indicar, por um lado, que o nível de conhecimento sobre plágio é similar entre estudantes que cursaram essa disciplina e os que não a cursaram, por outro lado, os autores notaram que o assunto é "pouco discutido em sala de aula" e o conhecimento que se tem sobre ele é muito intuitivo e equivocado.

Naturalmente, também cabe às instituições a adoção de medidas de controle e correção, tais como o uso de instrumentos de detecção do plágio, bem como a prescrição e imputação de sanções, pois a ordem social em todas as suas esferas também é mantida por meio desses dispositivos. Não é diferente no meio acadêmico. Sobretudo considerando-se a possibilidade de que parte dos estudantes produza trabalhos acadêmicos deliberadamente de forma plagiada, utilizando diferentes modalidades: reprodução de trabalhos comprados ou feitos por amigos e entregues em outras instituições (plágio consentido), transcrição de citações de outros trabalhos (plágio de fontes) justapostas em um texto aparentemente novo (pastiche) etc. 
Em consonância com a literatura apresentada e os dados obtidos, este estudo permitiu verificar ainda que o enfrentamento do plágio no ambiente acadêmico tem a ver com a mudança das práticas institucionais que favorecem que o plágio seja evitado, mais do que punido.

É o caso da adoção de medidas institucionais e preventivas que contribuem positivamente no enfrentamento do plágio acadêmico, tais como o posicionamento claro da instituição de ensino sobre o plágio, servindo-se dos veículos de comunicação acadêmicos disponíveis, entre eles suas home pages, por meio das quais se podem oferecer a toda comunidade educativa orientação prática sobre o que é, como se caracteriza, como se evita, tudo fartamente exemplificado.

Como verificado neste estudo, isso faz parte do conjunto de ações que vêm sendo desenvolvidas pelas instituições de ensino superior ao redor do mundo. Naturalmente, não se trata de encará-las como panaceia para o plágio, pois, como apontado pela literatura, esta é uma realidade que está integrada historicamente ao hábito de produção intelectual. Contudo, medidas de enfrentamento do plágio são necessárias para que esse problema não se torne insuportável ou, na pior das hipóteses, banalizado, o que corresponde a uma das maneiras apontadas por Schneider (1990, p. 35) para dizer que o plágio não é um problema: não percebê-lo em nenhum lugar.

Note-se que, apesar de o conjunto dessas iniciativas serem adotadas pelas universidades internacionais, as estimativas da ocorrência do plágio consideram que um terço dos estudantes universitários americanos cometem plágio ou algum tipo de fraude acadêmica (Posner, 2007, p. 8). Apesar de significativo, é um número que pode ser considerado pequeno se comparado ao Brasil. Embora ainda não se disponha neste país de estudos representativos que estimem a ocorrência do plágio em trabalhos acadêmicos, chama-se a atenção para a evidenciação feita por Garcia (2006) de que um grande número de professores universitários brasileiros (82,7\%) alegam já ter se deparado com trabalhos acadêmicos plagiados. Ou seja, as medidas de enfrentamento do plágio adotadas pelas instituições internacionais não as purificam dessa chaga do sistema intelectual, mas podem ser consideradas fundamentais para a redução da ocorrência do plágio em trabalhos acadêmicos.

\section{CONCLUSÃO}

O plágio é assunto antigo e sua prática vem aumentando, entre outros fatores, em virtude do desenvolvimento tecnológico. O plágio é preocupante especialmente no âmbito acadêmico, espaço no qual a produção escrita é uma demanda importante.

Este estudo permitiu a identificação das ações que podem contribuir para o enfrentamento do plágio de acordo com a literatura e os documentos das home page das melhores universidades do mundo. As abordagens encontradas foram classificadas em conjuntos de medidas institucionais, preventivas, diagnósticas e corretivas, por meio das quais se evidencia a responsabilidade das instituições de ensino no enfrentamento desse problema. 
O conjunto de ações mais comuns no enfrentamento do plágio refere-se às estratégias de informação e capacitação. A abordagem formativa, que corresponde, por exemplo, à promoção de cultura de integridade acadêmica, em geral tem se apresentado pouco adotada, embora a literatura consultada indique que isso tem impacto positivo em relação à prevenção do plágio no ambiente universitário.

Finalizando, apresenta-se como proposta de enfrentamento do plágio no meio acadêmico o emprego de esforços das instituições de ensino na adoção de políticas relacionadas ao assunto, bem como a criação de conteúdos e estratégias acadêmicas para a mitigação desse problema, tais como: adoção de Códigos de Ética, apresentação de conteúdo relacionado ao plágio nas home page das universidades brasileiras, integração do estudo sobre escrita acadêmica e plágio em matéria específica da grade dos cursos superiores.

\section{REFERÊNCIAS}

Barbastefano, Rafael Garcia; Souza, Cristina Gomes de. Percepção do conceito de plágio acadêmico entre alunos de engenharia de produção e ações para sua redução. Revista Produção Online, Florianópolis, edição especial/dezembro de 2007. Disponível em: <http:// www.periodicos.ufsc.br/index.php/producaoonline/article/viewFile/4877/4220>. Acesso em: 24 nov. 2009.

BorniA, Antonio Cezar. Evitando o plágio na dissertação. 2009. Disponível em: <www.eps. ufsc.br/ diomario/arquivos/plagiobornia.doc>. Acesso em: 24 nov. 2009.

Christofe, Lilian. Intertextualidade e plágio: questões de linguagem e autoria. 1996. $192 \mathrm{f}$. Tese (Doutorado em Linguística) - Universidade Estadual de Campinas, Campinas, 1996. Disponível em: <http://libdigi.unicamp.br/document/?code=vtls000115064> Acesso em: 17 nov. 2009.

Clemson University. The Center for Academic Integrity: Rutland Institute for Ethics. Disponível em: <http://www.academicintegrity.org/>. Acesso em: 28 nov. 2010.

CyBermetrics Lab. Webometrics Ranking of World Universities. 2009. Disponível em: <http:// www.webometrics.info/index.html>. Acesso em: 20 nov. 2009.

Fachini, Gilson Jober; Domingues, Maria José Carvalho de Souza. Percepção do plágio acadêmico entre alunos de programas de pós-graduação em administração e contabilidade. 2008. Disponível em: <www.ead.fea.usp.br/semead/11semead/resultado/trabalhosPDF/842.pdf>. Acesso em: 29 nov. 2009.

Faculty of ARTS And ScIEnces. Handbook for student 2009-2010: Harvard College. Disponível em: <http://webdocs.registrar.fas.harvard.edu/ugrad_handbook/current/ ugrad_handbook_single.pdf>. Acesso: 18 dez. 2009.

Furtado, José Augusto Paz Ximenes. Trabalhos acadêmicos em Direito e a violação de direitos autorais através de plágio. Jus Navigandi, Teresina, ano 7, n. 60, nov. 2002. Disponível em: <http:/jus2.uol.com.br/doutrina/texto.asp?id=3493>. Acesso em: 26 nov. 2009. 
Garcia, Pedro Luengo. O plágio e a compra de trabalhos acadêmicos: um estudo exploratório com professores de administração. 2006.130 f. Dissertação (Mestrado em Administração) Faculdade Cenecista de Varginha, Varginha-MG, 2006.

Haar, Ewout ter; Rezend, Daisy de Brito; Guimarães, Carla da Costa. Plágio. 2005. Disponível em: <http://euclides.if.usp.br/ ewout/ensino/fge2255/000190.html>. Acesso em: 24 nov. 2009.

Harvard College. Writing Program. Disponível em: <http://isites.harvard.edu/icb/icb. do?keyword=k24101>. Acesso em: 20 nov. 2009.

KYOTO UnIVERsity. 2009. Disponível em: <http://www.sg.kyoto-u.ac.jp/ja/programme/ courses/article/Professional\%20Writing> Acesso em: 23 nov. 2009.

LEVY, Pierre. A inteligência coletiva: por uma antropologia do ciberespaço. 3. ed. São Paulo: Loyola, 2000.

Manso, Eduardo J. Vieira. O que é direito autoral. São Paulo: Brasiliense, 1987 (Coleção Primeiros Passos, n. 187).

McCabe, Donald L.; Trevino, Linda Klebe; Butterfield, Kenneth D. Cheating in Academic Institutions: A Decade of Research. Ethics and Behavior, 11.3, p. 219-231, 2001. McCabe, Donald L; Pavela, Gary. New Honor Codes for a New Generation. Inside Higher Education, 11 mar. 2005. Disponível em: <http://www.insidehighered.com/ views/2005/03/11/pavela1>. Acesso em: 9 ago. 2010.

MCCORD, Alan. Improving online assignments to deter plagiarism. Lawrence Technological University, 2008. Disponível em: <http://etec.hawaii.edu/proceedings/2008/McCord2008. pdf $>$. Acesso em: 18 nov. 2009.

Marconi, Marina de Andrade; LaKatos, Eva Maria. Técnicas de pesquisa. 7. ed. São Paulo: Atlas, 2008.

MARTins, Joberto Sérgio Barbosa; SANTANA, Joseval de Melo. Um sistema para deteç̧ão de plágio em ambiente de aprendizado virtual. 2003. Disponível em: <http://www.nuppead. unifacs.br/artigos/Paper-JobertoMartins-fpve03\%20Joberto.pdf>. Acesso em:24 nov. 2009. Massachusetts Institute of Technology. Academic Integrity: A handbook for students. 2007a. Disponível em: <http://web.mit.edu/academicintegrity/handbook/handbook.pdf〉. Acesso em: 20 nov. 2009.

.Academic Integrity: Avoiding Plagiarism - What It Is? 2007b. Disponível em: <http:// web.mit.edu/academicintegrity/plagiarism/what-it-is.html>. Acesso em: 20 nov. 2009.

MAXwELL, Joseph Alex. Qualitative research design: an interactive approach. Thousand Oaks: Sage, 1996 (Applied Social Research Methods Series, v. 41).

MonAsh University. Plagiarism procedures: parent policy. 2009. Disponível em: <http:// www.policy.monash.edu/policy-bank/academic/education/conduct/plagiarism-procedures. html >. Acesso em: 21 nov. 2009.

National Taiwan University. Guidelines for Ph.D. and Master Degree Examination. 2004. Disponível em: <http://www.aca.ntu.edu.tw/esec2007/doc/13.pdf>. Acesso em:23 nov. 2009. 
. Composition Course: Guidelines for Composition 1 and 2. 2009. Disponível em:<http://www.forex.ntu.edu.tw/download.php?filename=147_5b9496af. doc\&dir=archive\&title=\%E4\%>. Acesso em: 11 mar. 2011.

. Guidelines for programming assignment \# 1. 2010. Disponível em: <http://cc.ee. ntu.edu.tw/ ywchang/Courses/Alg/prog1_sorting.pdf>. Acesso em: 11 mar. 2011.

OliveIRA, Marta Melo de. Plágio na constituição de autoria: análise da produção acadêmica de resenhas e resumos publicados na internet. 2007. 150 f. Dissertação (Mestrado em Letras) - Universidade Presbiteriana Mackenzie, São Paulo, 2007. Disponível em: $<$ http://mx.mackenzie.com.br/tede/tde_busca/arquivo.php?codArquivo=289>. Acesso em: 17 nov. 2009.

Oliveira, Márcia G. de; Oliveira, Elias. Uma metodologia para detecção automática de plágios em ambientes de educação a distância. In: Congresso BRASILEIRO DE ENSINO Superior A Distância - Esud, 2008, Gramado. Anais... Gramado, 2008. p.1-20. Disponível em: <http://200.169.53.89/download/CD\%20congressos/2008/V\%20ESUD/trabs/t38670. pdf $>$. Acesso em: 24 nov. 2009.

PÉcora, Alcir. Problemas de redação. São Paulo: Martins Fontes, 2002.

PERISSÉ, Gabriel. Nossos filhos não sabem usar o mouse ético. Revista Máxxima, n. 1, p. 12-14, ago. 2006. Disponível em: <http://www.revistamaxxima.com.br/> Acesso em: 2 ago. 2006.

Posner, Richard A. The little book of plagiarism. New York: Pantheon Books, 2007.

Plagiarism.org. Facts about plagiarism. Disponível em: < http://www.plagiarism.org/ plag_facts.html>. Acesso em: 24 nov. 2009a.

PlagiarisM.ORG. Facts about plagiarism. c2009. Disponível em: <http://www.plagiarism. org/plag_facts.html> Acesso em: 24 nov. 2009b.

QuéAu, Philippe. Cibercultura e infoética: grandes panoramas do século 21. Portal MultiRio, jan. 2007. Disponível em: <http://www.multirio.rj.gov.br/seculo21/texto_link. asp?cod_link=2298cod_chave=3\&letra=c>. Acesso em: 17 nov. 2009.

SCHNEIDER, Michel. Ladrões de palavras. Ensaio sobre o plágio, a psicanálise e o pensamento. Tradução de Luiz Fernando P. N. Franco. Campinas: Editora da UNICAMP, 1990.

STANLICK, Nancy. An open letter to faculty: some thoughts on plagiarism from "colonel cheatbuster". Faculty Focus, v. 7, n. 4, out. 2008. Disponível em: <http://www.fctl.ucf.edu/ Publications/FacultyFocus/content/2008/october.pdf>. Acesso em: 11 nov. 2009.

Swiss Federal Institute of Technology Zurich. Plagiarism: Information Notice for Students. 2008. Disponível em: <http://www.ethz.ch/students/semester/plagiarism_s_ en.pdf>. Acesso em: 20 nov. 2009.

The Australian National University. Policy: Code of Practice for Student Academic Integrity. 2009. Disponível em: <http://policies.anu.edu.au/policies/code_of_practice_for_ student_academic_integrity/policy>. Acesso em: 21 nov. 2009.

Universidade Estadual de Campinas. Tópicos Especiais em Ciência Politica III. 2005. Disponível em: <http://www.ifch.unicamp.br/graduacao/disciplinas/semestre205/ disciplinas/HZ344A.pdf>. Acesso em: 24 nov. 2009. 
Universidade de São PaUlo. Sobre plágio. 2009a. Disponível em: <http://www.ime.usp. $\mathrm{br} / \mathrm{dcc} /$ home$/$ index.php?option=com_content\&view $=$ article\&id=22\&Itemid=47>. Acesso em: 24 nov. 2009.

.2009b. Disponível em: <http://www.ead.fea.usp.br/semead/11semead/resultado/ trabalhosPDF/842.pdf>. Acesso em: 24 nov. 2009.

Universidade Federal de SANTA Catarina. Disciplina: CIN 5008 - Fontes de Informação II.2006. Disponível em: <http://www.ced.ufsc.br/ ursula/5008/5008_aula2.html >. Acesso em: 24 nov. 2009.

University of CAmbriDge. Good academic practice and plagiarism. 2010. Disponível em: $<$ http://www.admin.cam.ac.uk/univ/plagiarism/>. Acesso em: 11 mar. 2011.

UnIVERSTTy of CAPE Town. Avoiding plagiarism: a guide for students. 2005. Disponível em: <http://www.uct.ac.za/downloads/uct.ac.za/about/policies/plagiarism_students.pdf>. Acesso em: 21 nov. 2009.

UnIVERsity OF OXFord. Plagiarism: educational policy and standarts. 2006. Disponível em: <http://www.admin.ox.ac.uk/epsc/plagiarism/index.shtml>. Acesso em: 11 mar. 2011. University Of Pretoria. Plagiarism policy document. 2008. Disponível em: <http://web. up.ac.za/default.asp?ipkCategoryID=11297\&subid=11297>. Acesso em: 21 nov. 2009.

University of Queensland. Statute n. 4: Student Discipline and Misconduct, 2008. Disponível em: $<$ http://www.uq.edu.au/senate/docs/statutes/statute-04.pdf $>$. Acesso em: 21 nov. 2009.

UnIVERSITY OF ToKio. In your words or others? 2006. Disponível em: <http://lecture. ecc.u-tokyo.ac.jp/ cwpgally/references/200610_Quoting_and_plagiarism_English.pdf>. Acesso em: 23 nov. 2009.

VAz, Telma Romilda Duarte. O avesso da ética: a questão do plágio e da cópia no ciberespaço. Cadernos de Pós-Graduação-Educação, São Paulo, v. 5, n. 1, p. 159-172, 2006. Disponível em: <www.uninove.br/PDFs/Publicacoes/cadernos.../cdposv5n1edu_2_13. pdf $>$. Acesso em: 24 nov. 2009.

\section{SOBRE O AUTOR}

Marcelo Krokoscz é professor assistente da Fundação Escola de Comércio Álvares Penteado (FECAP) e doutorando em educação pela Universidade de São Paulo (USP).

E-mail: krokoscz@uol.com.br

Recebido em fevereiro de 2011 Aprovado em julho de 2011 


\section{Evaluación del progreso de la Cooperación Académica Nacional - Nuevas Fronteras - edición 2007 y oportunidades de formación para las redes de cooperación y las tecnologías en áreas estratégicas de futuro}

Los resultados de la estadística descriptiva de una consulta a coordinadores de proyectos son presentados para evaluación de progreso of Programa Nacional de Cooperacion Académica - Nuevas Fronteras (2007). La metodología cualitativa consideró la comparación con los pareceres de los consultores especialistas que aprobaran la continuidad de los proyectos. Instituciones fueran mapeadas con potencial à la formación de redes de cooperación en las áreas estratégicas e tecnologías avanzadas indicadas en lo Libro Azul de la Cuarta Conferencia de Ciencia Tecnología y Innovación para lo Desarrollo Sustentable por medio de busca de ocurrencias no Directorio de Investigación del Conselho Nacional de Desenvolvimento Cientifico e Tecnológico (CNPq) para comparación con los programas de posgrado aprobados pela Coordenação de Aperfeiçoamento de Pessoal de Nivel Superior (CAPES) con grados mejores o iguales a cinco.

Palabras clave: evaluación de progreso; cooperación académica; redes; Nuevas Fronteras.

\section{MARCELO KROKOSCZ}

\section{Abordagem do plágio nas três melhores universidades de cada um de cinco continentes e do Brasil}

Este estudo visa identificar diferentes abordagens sobre o plágio; comparar as abordagens das melhores universidades mundiais com as universidades brasileiras; apresentar uma proposta de enfrentamento do plágio no Brasil. Realizou-se uma pesquisa descritiva documental com uma amostra não probabilística intencional extraída do Webometrics Ranking of World Universities. Constatou-se que nas universidades da Oceania, Europa e América o plágio é abordado de forma diversificada e abrangente, envolvendo medidas institucionais, preventivas, diagnósticas e corretivas. Verificou-se que nas universidades brasileiras o assunto praticamente não é abordado. Propõe-se as seguintes ações: atuação institucional no desenvolvimento da integridade acadêmica; definição e divulgação de política institucional; apresentação de conteúdo relacionado ao plágio nas home page das universidades brasileiras; integração do estudo sobre escrita acadêmica e plágio em matéria específica da grade dos cursos superiores.

Palavras-chave: plágio; abordagem universitária; medidas de enfrentamento. 


\section{Approach to plagiarism in the three best universities of each one of the five continents and Brazil}

This study aims to identify different approaches to plagiarism, to compare the approaches of the best universities in the world with Brazilian universities, submit a proposal for coping with plagiarism in Brazil. We conducted a descriptive research document with a non-probability sample drawn from the intentional Webometrics Ranking of World Universities. It was found that the universities in Oceania, Europe and America plagiarism is tackled diverse and comprehensive, involving institutional arrangements, preventive, diagnostic and corrective. It was found that in Brazilian universities, the subject is not approached. Proposes the following actions: institutional performance in the development of academic integrity, definition and dissemination of institutional policy, presentation of content related to plagiarism in the home page of the Brazilian universities, integrating the study of academic writing and plagiarism on the grid of specific courses higher.

Keywords: plagiarism; addressing university; measures of coping.

\section{Planteamiento de plagio en las tres mejores universidades de cada uno de los cinco continentes y de Brasil}

Este estudio tiene como objetivo identificar los diferentes enfoques al plagio, para comparar los enfoques de las mejores universidades del mundo, con universidades de Brasil, presentará una propuesta para hacer frente al plagio en Brasil. Se realizó un documento de investigación descriptiva con una muestra no probabilistica extraídas de la Webometrics Ranking intencional de Universidades del Mundo. Se encontró que las universidades de Oceanía, Europa y América del plagio se aborda diversa y amplia, con inclusión de arreglos institucionales, preventivas, de diagnóstico y correctivo. Se encontró que en las universidades brasileñas, el tema no se aborda. Propone las siguientes acciones: el desempeño institucional en el desarrollo de la integridad académica, definición y difusión de la política institucional, la presentación de los contenidos relacionados con el plagio en la página principal de las universidades brasileñas, integrando el estudio de la escritura académica y el plagio en la parrilla de cursos específicos más alto.

Palabras clave: plagio; enfoque académico; medidas de adaptación.

\section{EUNICE TREIN E JOSÉ RODRIGUES}

\section{O mal-estar na academia: produtivismo científico, o fetichismo do conhecimento-mercadoria}

O ensaio discute o mal-estar provocado pelo fetiche do conhecimento- mercadoria e o seu canto de sereia - produtivismo científico. Na tentativa de explicar 